Viso: Cadernos de estética aplicada

Revista eletrônica de estética

ISSN 1981-4062

$N^{\circ} 27$, jul-dez/2020

http://www.revistaviso.com.br/
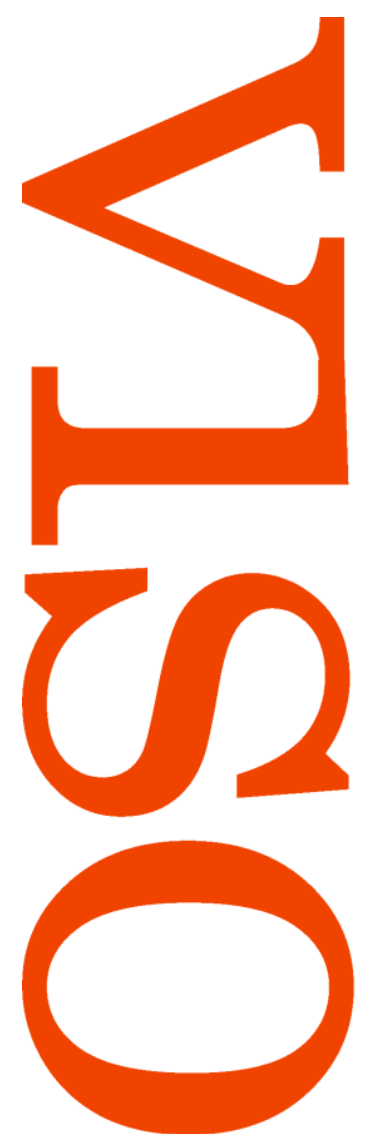

\title{
Emergência da superfície: A imagem sem profundidade, dos românticos a Andy Warhol
}

Fabiano Lemos 


\section{RESUMO}

Emergência da superfície: A imagem sem profundidade, dos românticos a Andy Warhol

Através de uma genealogia da função epistêmica da relação entre profundidade e criação na literatura e nas artes visuais, o artigo procura mostrar como as vanguardas contemporâneas precisaram formular um saber sobre a superfície que reconfigura o próprio sentido de uma hermenêutica da obra, do autor e do espectador. A fotografia se mostra, assim, exemplar nessa nova dinâmica, instaurando espaços de circulação identitária antes inexistentes.

Palavras-chave

romantismo alemão; filosofia das artes visuais; Andy Warhol

\section{ABSTRACT}

\section{Depthless imagery, from Romanticism to Andy Warhol}

This article is a contribution to the history of epistemological economy of superficiality, regarded as image device in visual arts, from its inauguratory understanding within German Romanticism to its developments in Andy Warhol's oeuvre.

Keywords

German Romanticism; philosophy of visual arts; Andy Warhol 
LEMOS, Fabiano. "Emergência da superfície: A imagem sem profundidade, dos românticos a Andy Warhol". Viso: Cadernos de estética aplicada, v. 14, $\mathrm{n}^{\circ}$ 27 (jul-dez/2020), p. 37-70.

DOI: 10.22409/1981-4062/v27i/378

Aprovado: 27.10.2020. Publicado: 28.12.2020.

(C) 2020 Fabiano Lemos. Esse documento é distribuído nos termos da licença Creative Commons Atribuição-NãoComercial 4.0 Internacional (CC-BY-NC), que permite, exceto para fins comerciais, copiar e redistribuir o material em qualquer formato ou meio, bem como remixá-lo, transformá-lo ou criar a partir dele, desde que seja dado o devido crédito e indicada a licença sob a qual ele foi originalmente publicado.

Licença: http://creativecommons.org/licenses/by-nc/4.0/deed.pt_BR

Accepted: 27.10.2020. Published: 28.12.2020.

(C) 2020 Fabiano Lemos. This document is distributed under the terms of a Creative Commons Attribution-NonCommercial 4.0 International license (CC-BY-NC) which allows, except for commercial purposes, to copy and redistribute the material in any medium or format and to remix, transform, and build upon the material, provided the original work is properly cited and states its license.

License: http://creativecommons.org/licenses/by-nc/4.0/ 
para aquela Noéli, através da baía.

\section{Fantasmagoria do olhar}

No nível especificamente ontológico, a transformação técnica e epistemológica que deu lugar às imagens fotográficas desde sua invenção técnica, entre as décadas de 1820 e 1840, está anunciada em duas figuras - literárias, mas também sociais que, refinadas, não por acaso, pelo Romantismo, colocam em jogo a relação que o par ver-não ver mantém com a verdade. São elas: o fantasma e o duplo.

Quanto à primeira dessas figuras, sabemos de sua importância para a constituição daquilo que ficou conhecido como literatura de horror. Mas, mais do que um gênero definido por um objeto, o que ela coloca no centro da narrativa é justamente a intuição de que o sentido manifesto é uma ausência. Não simplesmente de modo negativo, ou seja, como a revelação de um truque: um personagem que parece estar lá, mas, na verdade, já morreu, ou está em outro lugar. Antes disso, o mais fundamental naquilo que Stefan Andriopoulos recentemente chamou de "aparição espectral" no romance gótico alemão e seus antecessores é que ela é um acontecimento em sua positividade. Nesse sentido, os românticos irão radicalizar (e manipular pelo avesso) um aspecto que, de certa forma, já estava presente em Kant, quando esse compreendeu a ilusão transcendental como constitutiva - e não meramente um erro. ${ }^{1}$. Há aqui uma troca de sinais, evidentemente - e isso muda tudo. 0 que na filosofia crítica transcendental caracteriza um problema que poderia ser remediado ao limitarmos o espectro do sentido, restringindo a imagem do que podemos saber - ao ajustarmos o foco, poderíamos dizer -, entre os românticos será assumido como lugar mesmo da verdade. 0 fantasma dá a ver a instabilidade ontológica estrutural: nem esse, nem aquele; nem vivo, nem morto; nem antes, nem depois; ele é o elemento revelador de um espaço indeterminado, intermediário e incompleto, único capaz de fazer surgir uma epifania do sentido. 
Sob esse aspecto, os textos de E. T. A. Hoffmann são exemplares, embora, nem de longe, únicos. Seus personagens estão sempre submersos em um mondo óptico singular, que se desencadeia em torno de uma aparição qualquer. 0 instante dessa visão inicial se desdobra em um discurso que hesita, em suas obras, entre dois polos opostos: o totalmente iluminado e o invisível. De certa maneira, há um olho que se abre intermitente sobre tudo, retesado com a plenitude de luz que ele captura. Assim, acompanhamos a cena que serve de leitmotiv em 0 homem da areia, em que Nathanael vê, horrorizado, a figura demoníaca de Coppelius, que o obsedará até a loucura e a morte e que, desde o começo, ele acreditará ser o assassino de seu pai. Atormentado pela imagem de Coppelius, Nathanael tensiona seu olhar até o limite - "não consegui fechar os olhos" ${ }^{2}$, ele diz -, do mesmo modo que todos os olhares ao seu redor estão abertos e luminosos em demasia - o de Coppelius é, sobretudo, "faiscante" [funkelnden] (Idem). ${ }^{3}$ Esse paroxismo visual, no entanto, não deve enganar. Ele cega e não decifra. A imagem que a ele está vinculada é imprecisa ou insuportável, ela se esconde a céu aberto. No conto Don Juan, Hoffmann traduz esse princípio através da passagem da ópera homônima de Mozart que ele mantém em italiano no texto: "Ma qual mai s'offre, o Dei, spetacolo funesto agli occhi miei! - Mas que espetáculo funesto, ó Deus, se oferece aos meus olhos!". ${ }^{4}$ A contrapartida dessa luminosidade total, entretanto, é a constante iminência da cegueira. Afinal, Coppelius é o homem da areia, o Sandmann, "homem mau que vem até as crianças quando elas não querem ir para a cama, e Ihes joga punhados de areia nos olhos, que, então, saltam ensanguentados da cabeça, e, assim, ele os joga no saco e os leva até a lua crescente [...]". ${ }^{5}$ Somente esse olho, entre retesado e arrancado, é capaz de enxergar a imagem fantasmática, sendo, ele mesmo, ambíguo.

A imagem fantasmática - e é nisso que ela antecipa a imagem fotográfica - se produz através de uma revelação que não pode ser uma síntese. É extremamente sintomático que a revelação do horror fantasmagórico cause uma irrestrita loucura entre os personagens de Hoffmann. Essa é a chave 
interpretativa que assinala o momento de verdade embutido no suicídio de Nathanael ao final de 0 homem da areia. Suas últimas palavras nem sequer são mais suas, já que ele as pronuncia com as idiossincrasias do acento estrangeiro de Coppola (que nada mais é senão Coppelius duplicado): "Belo olho - belo olho [ele diz: Sköne Oke - sköne Oke, e não, como em alemão correto: Schönen Augen]" ${ }^{6}$ A imagem final é, antes, um deslocamento ontológico amplo: o que Nathanael vê é aquilo que se apresenta como ausente. Não, como pensou Freud ao ler esse texto, por uma configuração patológica qualquer, mas porque essa é, na narrativa de Hoffmann, a própria estrutura do mundo. Nesse ponto, é esse mundo que atinge sua expressão mais incontornável, e sua instabilidade contamina os personagens. A loucura final de Nathanael, o fato de que ele se perde, de que ele não é mais ele mesmo, mas um outro que, inclusive, fala por ele, com o sotaque do outro - esse fato não é o significado oculto de uma punição ou degeneração, mas a revelação da imagem da verdade.

Uma tal revelação é ainda mais enfática no caso das fotografias de fantasmas, que surgiram ainda na década de 1860. Não que já não houvesse uma interseção entre o mundo dos espíritos e o das imagens antes da invenção da fotografia, mas é sintomático que ela só tenha podido se dar até então sob a forma de uma visão, cujo médium seria, precisamente, a mão do artista. As pinturas automáticas eram, incontornavelmente, mensagens visuais que os mortos enviavam aos vivos, seja para confortá-los, ensiná-los ou corrigi-los. De todo modo, a presença espiritual nunca se manifestava em si mesma, o espírito e seu olho não se davam a ver fisicamente; eram, antes, ainda a condição transcendental (em um sentido kantiano), e preservavam a direção do circuito código-decodificador-linguagem, tipicamente clássico, de modo que seu automatismo era limitado pelo médium. ${ }^{7}$ Com as fotografias de fantasmas, esse sujeito da eternidade em devir, que é o espírito, realiza, em termos visuais, a dialética sujeito-objeto romântica, pós-kantiana: ele continua sendo um agente do sentido, na medida em que interfere na imagem e a condiciona, mas só o faz sob o preço de ser, ele mesmo, 
revelado. É verdade que nem sempre de forma completamente reconhecível à primeira vista. Sabemos que muitas das fotografias de fantasmas, em especial após 1880, com o desenvolvimento das técnicas químicas, eram produzidas a partir de imagens pré-gravadas até certo ponto nas placas de vidro, e, depois, plenamente desenvolvidas, na mesma placa, junto a outras imagens - o que possibilitou a justaposição mais exata dos vivos e dos mortos, fazendo com que aqueles posassem exatamente entre dois parentes, ao lado da cadeira, por sobre seus entes queridos etc. ${ }^{8}$ Mas o fato é que os avanços técnicos não veicularam uma maior nitidez representativa dos fantasmas: ao contrário, quanto mais desenvolvido o método e o material científicos da fotografia, mais difuso se tornaria o contorno do espectro. 0 que, para muitos contemporâneos dessas aparições disformes, era considerado uma prova de sua falsidade ${ }^{9}$, era, na verdade, o desenvolvimento do destino não-representacional da nova economia da visualidade. Hyppolite Baraduc, por exemplo, fotógrafo de espíritos e pesquisador típico do Romantismo francês tardio - por suas convicções que mesclavam positivismo e misticismo - produziu uma série de fotografias em que os espíritos se deixam ver como véus, manchas imprecisas, interferências mais perturbadoras para um certo público justamente porque elas se recusavam a ceder ao olho clássico e o pervertiam, presentificando-se em mistério. ${ }^{10}$ Seguindo a nomenclatura inventada quase vinte anos antes pelo barão von Reichenbach, em $1845^{11}$, Baraduc chamou a forma fotográfica do espírito de od. Podemos dizer, assim, que as forças ódicas só revelavam sua natureza na superficialidade fotográfica. E se, como afirma John Harvey, "o fotógrafomédium celebrou o casamento do céu e da terra, dos mortos e dos vivos, sobre a superfície de uma placa de vidro" ${ }^{12}$, isso só foi possível até certo ponto. Seu controle era muito mais limitado - e, em última instância, falso - do que o do pintor, uma vez que a imagem que deveria aparecer ao final do processo era - ou, ao menos após a compreensão ódica da figura do fantasma - imprevisível. 
A segunda figura ontológica que instancia a nova economia da visualidade fotográfica é a do duplo. Ela mantém com o fantasma um elo de copertencimento indiscutível, mas tem sua especificidade: o duplo esboroa a fronteira entre distinção qualitativa e distinção quantitativa. Ao surgir, ele perturba a identidade do sujeito com seus esquemas e sínteses. Os personagens de Hoffmann são, quase sempre, uma intercessão entre a fantasmagoria e a duplicidade. Assim, Coppola, em 0 homem da areia, como vimos, é um fantasma: ele emerge de um passado que teima em persistir. Mas é, também e fundamentalmente, um duplo: sua aparição solicita o horror da semelhança sob a forma de uma insondável diferença, e é nisso que reside seu potencial aterrorizante.

A prima facie da importância do duplo como figura ontológica se mostra, além de Hoffmann, nas obras de Dostoievski, Jean Paul, Poe, Chamisso e muitos outros - em geral elencados pelo indexical estudo de Otto Rank, 0 duplo, publicado originalmente em 1914. Seguindo os procedimentos interpretativos de seu mestre Sigmund Freud, Rank procurou levar o tema da duplicação ao âmbito psicanalítico, mas, com isso, acentuou sua característica mais fundamental: a indiscernibilidade. Isso porque, como lembra, os duplos podem bem ser "uma separação [Abspaltung] do eu, tornada independente e visível", como "pessoas reais e corpóreas com semelhança exterior extraordinária". ${ }^{13}$ Essa Abspaltung é, podemos dizer, a resposta de um certo Romantismo, mais subversivo e completamente incompatível, sob esse aspecto, com sua versão hegeliana, ao paradigma sintético da subjetividade crítico-transcendental. 0 duplo faz da inconclusividade e do tensionamento a experiência central da manifestação do sentido, e, ao confundir dentro e fora, eu e outro, semelhança e diferença, conduz o problema da representação ao da superfície.

Uma leitura mais generosa com os discursos do século XIX, no entanto, logo mostra que o lugar do duplo não se limita à literatura. Antes dessa distinção heurística, ele já se encontra inoculado na própria noção de autoria desenvolvida pelos românticos nos domínios mais diversos. Em sua versão mais 
radical, o Romantismo sublinhava o aspecto comunitário de uma obra ao mesmo tempo em que deslocava a assinatura dos nomes para o regime da instabilidade. Que Friedrich Schlegel surja como autor dos fragmentos da Athenäum em 1798, isso não o impediu de se reapropriar, autorizadamente, de textos de seu irmão mais velho, de Novalis ou de Schleiermacher. Da mesma maneira, a colaboração etnográfico-linguística dos irmãos Grimm permitiu a emergência de uma série de disciplinas antes inexistentes - e isso exatamente na medida em que seus nomes se confundiam e, mais do que isso, apelavam ao arcabouço anônimo das tradições narrativas germânicas. Essa reconfiguração da unidade identitária do autor teve consequências extremamente duradouras - embora ainda não adequadamente avaliadas, até onde vejo - e redimensionaria a própria relação entre interioridade $\mathrm{e}$ exterioridade das obras de arte no contexto de uma longa dinastia, que iria de Goethe e Schiller a Deleuze e Guattari, passando pelas irmãs Brontë e por Marx e Engels.

É também o objeto em geral que se duplica, ou melhor, se multiplica. Poder-se-ia dizer que, a princípio, as vertigens dessa multiplicação ainda foram retificadas pelo paradigma da representação. 0 uso do estereoscópio, por exemplo, remete precisamente a esse esforço de dominação: inventado antes da fotografia, é só com ela que ele se desenvolve como um aparelho que, pelo efeito das lentes internas e de um visor binocular, traduzia duas imagens separadas, ligeiramente diferentes em relação ao ângulo em que haviam sido tiradas, em uma única e vívida figura. ${ }^{14}$ Ao produzir o efeito tridimensional a partir do desnível mínimo que separava duas imagens, ele se constituiu como o aparelho que permitiu reconduzir o risco da disjunção à pacificação da síntese - um tanto fantástica, é verdade, mas apenas na medida certa. 0 estereoscópio libera o perigo da instabilidade dos objetos através do prazer, atestado por sua enorme popularidade entre 1850 e 1880, obtido nessa "experiência do simulacro". ${ }^{15}$ Não é nele, portanto, que devemos procurar o duplo como figura ontológica, mas nos problemas da cópia e da pose - e naquilo que as torna possíveis. 
Pelos esquemas históricos apresentados até aqui, já se pode perceber que a investigação em torno da possibilidade de produzir cópias de imagens fotográficas se confunde com a própria trajetória das invenções que permitiram capturá-las. 0 surgimento do negativo, em sua tradutibilidade progressiva e virtualmente infinita em positivos, acabou soterrando a estrutura da singularidade dos primeiros processos - ainda que, por motivos políticos, tenha demorado um pouco a conseguir fazê-lo. Essa estrutura ainda está operante no daguerreotipo, por exemplo. Nele, a placa de estanho quimicamente sensibilizada se confundia com a própria imagem, já que não podia ser duplicada, tornando-se única. É somente com o calótipo de Talbot que se permite a formação de um negativo e, com isso, de várias cópias em papel, desarticulando o suporte da imagem (e, com isso, tornando o problema do suporte uma questão central na economia da fotografia). Dessa maneira, não apenas se abriu o caminho para a possibilidade de uma manipulação universal da fotografia, que os filmes amadores da Kodak consolidaram desde a passagem para o século $X^{16}{ }^{16}$ mas, mais que isso, 0 negativo permitiu ampliações, reduções, edições, e a imagem em papel pôde, a partir de então, "ser inserida em livros e álbuns, anexada a documentos e enviada pelo correio, bem como enquadrada e pendurada na parede" ${ }^{17}$ Desonerada do trauma do acontecimento único, podia, enfim, circular. Das pranchas anatômicas fotográficas ao espetáculo do fotojornalismo, o objeto já não se conformava em ser substituído por um outro código - um relato ou um desenho -, mas se duplicava, presente-ausente, e fazia todo acontecimento retornar, ainda que, para lembrarmos de Nietzsche, sob a forma da diferença. Assim, o que parece ser apenas uma diferença de graus, de intensidade dos processos circulatórios, faz as vezes, antes, de uma diferença de natureza: a circulação infinita é um princípio constitutivo, e não contextual, das imagens fotográficas.

Se a ideia de cópia ainda deixava uma margem suficientemente ampla para a reinserção dos aspectos identitários do simulacro, a questão da pose parece minar as esperanças no 
encontro com o real. É verdade que ela já se colocava com a pintura, mas em um registro consideravelmente diferente. A pose na pintura é uma ideia negociada entre o pintor e seu objeto, e se manifesta em um regime de temporalidade tão amplo que, se não se confunde com a passagem do tempo real, ao menos extrai dele uma amostra tão longa que lhe serve de enquadramento, ou seja, o reduz enquanto o preserva. 0 tempo dos museus insiste nessa demora do olhar - e, mesmo que hoje em dia a fotografia tenha entrado nesse espaço, ela não Ihe pertence (ou, ao menos, não pertence ao modelo museológico clássico). O lugar da fotografia é o álbum voltarei a isso mais adiante - e é fácil entender, comparativamente, que, por mais que, em seus primórdios, o procedimento dos fotógrafos demandasse um longo tempo de exposição, ele certamente era mínimo perto daquele exigido por Velásquez ou, para tomar um exemplo mais recente, Lucian Freud de seus modelos. 0 que antes supunha meses para a revelação, agora, no máximo - e estamos falando de 1827 ainda - precisamos esperar sete ou oito horas. A pose na fotografia rompe com o espaço iluminista da negociação e se instaura como marca do real. $\mathrm{Na}$ pintura, os movimentos podem ser corrigidos pelo pintor, bem como a variação de luz, a inquietude de uma criança ou de um animal. Na fotografia, é preciso manter, a qualquer preço, a rigidez da pose; não há intermediação possível. Com isso, a duplicação entre o objeto e sua imagem se inscreve na superfície mesma do papel (ou do metal, ou do vidro) e como que se autonomiza materialmente, criando um código próprio no limite entre o visual e o invisível. Pensemos nas mães que se colocavam atrás de um pano negro e seguravam seus filhos pequenos para que mantivessem o equilíbrio durante a longa espera diante da câmera - ou, pelo mesmo motivo, nas colunas, cadeiras e outros móveis e adereços que serviam de apoio aos mais adultos nos primórdios da arte fotográfica. A pose aí rasura o real ao se confrontar com ele enquanto instantâneo, e impõe todo um complexo léxico da fronteira verdadeiro-falso, que é, acima de tudo, uma renovação criativa (e aberta) dos sistemas de objetos - embora, para alguém como Siegfried Kracauer, 
apenas instale uma estética massificada. Mas, ao contrário do que pretendem os detratores do kitsch, não seria ele, também, o lugar de uma confusão a ser explorada? Duplo posado da obra de arte, ele, no mínimo, coloca em questão os padrões de circulação e tangibilidade dos objetos artísticos, e torna possível uma disseminação incontrolável daquilo que Martin Parr denominou "as delícias do vernáculo imagético". ${ }^{18}$

Didi-Huberman chega à mesma conclusão: "no plano temporal, uma pose é extirpada de um movimento, de uma tensão, uma pose é uma intermitência, há nela uma separação interna da imagem do corpo. [...] Uma espécie de instabilidade geral das imagens só pode ser uma consequência disso". ${ }^{19}$

A pose é a resposta simbólica ao problema da limitação técnica da câmera. Se Jens Jäger tem razão, "fotografias nas quais os homens eram retratados pelo fotógrafo e pela câmera desprotegidamente como meros objetos eram, nesse período, praticamente impossíveis". ${ }^{20}$ É exatamente esse signo tangível da imprevisibilidade insistente, ou seja, do ontologicamente instável, contra o qual se arma, em vão, Nietzsche no momento em que se coloca diante da câmera. Em uma carta de 6 de agosto de 1868, ele envia a seu amigo Rhode uma fotografia sua em rígida pose militar, segurando um sabre, e acrescenta:

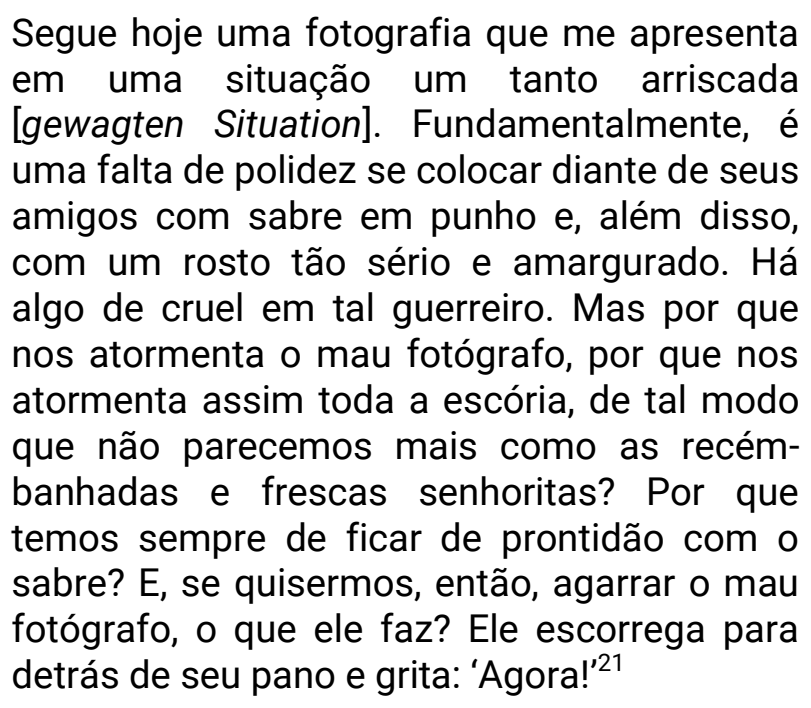

Apesar de ter posado um número relativamente grande de vezes para retratos, Nietzsche sempre se sentiu profundamente incomodado com a instantaneidade da imagem fotográfica, 
embora insista em reconhecer sua causa na figura do mau fotógrafo, antítese lógica de uma metafísica do gênio persistente ainda em sua obra. Seja como for, o risco da duplicação própria da pose é potencializado pelo anonimato do autor que, para dar a ver, se eclipsa, escorrega - er kriecht, diz Nietzsche - e escapa, deixando a marca de sua ausência. Sem a mão do artista, a pose é essa espécie de máscara mortuária capaz de tragar tudo para a morte. Nesse sentido, Ernest Chesneau, em seu romance $A$ quimera, de 1879, dá voz a toda uma geração de artistas que se servia das fotografias como modelos para suas pinturas e desenhos, mas apenas para restaurar-lhes, com o pincel ou o lápis, uma vida que a burguesia, já acostumada ao "retrato gélido" do daguerreotipo, havia perdido. Somente quando pinta o retrato da condessa de Cermont é que seu personagem, Gaston de Charly, faz com que a imagem fotográfica, que ele mesmo havia obtido, seja reerguida ao nível do real. ${ }^{22}$ Essa caracterização de Charly bem podia ser a de Delacroix, pelo modo como se serviu das fotografias de Eugène Durieu. ${ }^{23}$ Nietzsche, Chesneau e Delacroix constituem, assim, a contrapartida, ou melhor, o negativo da renovação criativa dos códigos dos objetos possibilitada pela pose.

Assim, tanto o fantasma quanto o duplo colocaram - sob muitos aspectos em ruptura com a tradição que lhes antecedeu - o problema da assinatura ontológica: o primeiro, em relação ao par espaço-tempo; o segundo, em relação ao par mesmoOutro. Uma indeterminação quantitativa se impõe, de modo tão amplo, que só pode ter como resultado (ou sintoma?) uma mudança qualitativa das imagens. Sem cessar de se confundir - pela comunhão de uma instabilidade que está pressuposta em seu funcionamento - esses mecanismos promovem aquilo que, se quiséssemos fazer uma paródia de Kant, poderíamos chamar de recusa da unidade de apercepção transcendental. A fotografia é, com isso, fantasma e duplo do olhar. 


\section{Itinerário das derivas.}

Às transformações das estruturas ontológicas e dos esquemas perceptivos da imagem, a fotografia acrescentava, já nos seus primórdios, uma terceira mudança: aquela relacionada ao modo de circulação dos objetos fotográficos - ou, o que quer dizer o mesmo, aquela relacionada a uma experiência social do olhar. 0 espaço serial do álbum remodelou os termos nos quais uma identidade simbólica e uma unidade experiencial foram constituídas e articuladas.

De um modo ou de outro, as narrativas indenitárias de uma cultura - não apenas, mas também - se consolidaram como uma apropriação do tempo através do espaço. Com isso, integraram um horizonte de problematizações que, por exemplo, a teoria da arquitetura se colocaria como tarefa retomar frequentemente, pelo menos desde o final do século $X I X^{24}$, já que é nesse horizonte mesmo que podemos localizar as estratégias de autocompreensão de uma dada sociedade o modo como ela constitui, para si mesma, uma imagem. Isso fica claro, por exemplo, no tipo de experiência existencial construída nos edifícios clássicos. 0 espaço desenhado pelos afrescos de um palácio italiano na passagem do século $X V$ para o XVI, ou entre as paredes e seu teto, pode ter como efeito a condução a um regime temporal específico, a um "outro 'mundo', coexistente, mas diferente". ${ }^{25}$ Do mesmo modo, os salões parisienses que, durante o século XVII e parte do XVIII, pareciam muito mais depósitos abarrotados, foram reprojetados, no período pós-napoleônico, para criarem condições para uma experiência visual homogênea - por exemplo, através do agrupamento por temas. ${ }^{26}$ Seja como for, seria difícil encontrar na sala de um antiquarianista - como eram denominados os colecionadores de arte até o começo do século XIX - a geometria asséptica dos museus modernos, e é isso que torna a figura de Winckelmann, que elaborou uma teoria da arte a partir desses espaços pré-museológicos, tão excêntrica em relação ao regime de visualidade da arte do tempo de Hegel. ${ }^{27}$ É sintomático, enfim, que Friedrich Schinkel, arquiteto responsável pela construção do Altes Museum, em 
Berlim, inaugurado em 1820, tenha explicitamente se declarado contra a organização cronológica das obras de arte em seu interior, privilegiando uma experiência estética de caráter único e integral. ${ }^{28}$

Mas também a pintura comporta essa dimensão pública do olhar, e, nela, isso se inscreve no próprio interior da imagem. A conhecida análise que Foucault faz do quadro Las meninas, de Velázquez, no começo de As palavras e as coisas, se esforça em mapear os interditos que regem o espaço entre 0 representante e o representado, ou, antes, entre o espectador, 0 pintor e seu modelo. ${ }^{29} \mathrm{Em}$ uma interpretação que se afasta e se aproxima da de Foucault constantemente, Rosalind Krauss procurou mostrar que, já na segunda metade do século XIX, o modo de exibição das telas nas paredes dos museus acabou por substituir o privilégio da perspectiva ortogonal por uma reorganização diagonal dos planos da pintura, bem como afetou a noção de profundidade em função da mensuração prévia da imagem em relação ao espaço em que seriam exibidos os quadros. ${ }^{30} \mathrm{~A}$ parede do museu se desenvolvia, assim, como a condição abstrata e, ao mesmo tempo, como limite material imageticamente indexado, em uma lógica do compartilhamento da visualidade bem distinta daquela da fotografia. As coleções de cartes-de-visites podiam pertencer a uma determinada família, a um nome e a um tempo, mas sua manipulável portabilidade tornava provável que ela entrasse em um fluxo de objetos que as ressignificou de modo virtualmente infinito. Entre heranças e abandonos, as fotografias deslizam facilmente entre diferentes mãos - e diferentes identidades. Talvez se pudesse afirmar algo semelhante em relação aos quadros, esculturas e mesmo prédios. Mas na fotografia a maleabilidade mesma é o que explica o fato de que toda família, toda unidade cultural - agremiações, clubes, cultos e seitas - podem ser (e, em grande parte das vezes, são) colecionadores de imagens. Não se trata de uma diferença quantitativa, mas qualitativa. Isso significa dizer que a dimensão serial do álbum, que instaurava os mecanismos da sobreposição no interior da imagem fotográfica, também tornou o espaço de circulação de sua experiência um domínio 
indefinido. Como as pinturas, as fotografias podem ser destruídas ou reapropriadas, mas, nelas, esse movimento é contínuo, intrínseco - algo como sua destinação, no sentido que o esperançoso Kant dava ao termo Bestimmung.

Por isso, o esforço de conduzir a fotografia para a parede, de retirá-la da série e esterilizá-la como uma pintura, no museu ou no porta-retratos, pode acabar encobrindo a resistência que essas imagens opõem ao essencialismo do singular, e ao seu duplo cognitivo, o correspondencionismo. Somente por uma espécie de concessão que interferia profundamente na estrutura de circulação identitária é que se deu, historicamente, a emergência de um público consumidor de fotografia como arte. A visualidade museológica não comporta a fotografia senão retificando seus riscos, que são a tradução da instabilidade ontológica e gnosiológica no nível social e político.

Nesses termos, o risco da imagem fotográfica pode ser encontrado naquela zona de indiscernibilidade à qual pertencem, também, os fantasmas, o duplo e a pose. O Da de seu Dasein nunca está dado de modo sólido o suficiente; movediço, ele está comprometido com as passagens, os hiatos e os saltos da trajetória das atribuições de identidades. Mas para que o modo de existência da fotografia seja a circulação, é preciso que ela comporte uma certa leveza: material, sem dúvida, mas igualmente metafísica. Dito de outra maneira, é preciso que uma questão de valor se coloque com ela, que sua reprodutibilidade - sua repetibilidade -, ao solapar as pretensões de individualidade do objeto e do espectador, torne instável - porque indiferente - o contexto em que se inscreve. Ganha-se, com isso, uma velocidade de variação semiótica que chega a um nível onde o sentido é substituído pela sua potencialidade. Os rostos dos álbuns de uma família vitoriana talvez não possam mais ser reconhecidos por aquele que os vê, mas, colecionáveis, eles podem se reunir a outras séries, segundo outros critérios narrativos: podem retratar uma época, podem ser recortados e colocados em novos álbuns, podem se multiplicar em novos positivos e cópias, podem, por fim, ser 
digitalizados e percorrer distâncias insondáveis através da internet. Em grande medida, a digitalização das imagens fotográficas representa seu destino mais desenvolvido até agora, isso porque, com ela, o próprio suporte se tornou indeterminado, realizando, assim, sua vocação pós-Daguerre. A imagem virtual de um quadro de Rembrandt, por exemplo, é algo completamente diferente da visualidade exigida pela tela física. Mas o caráter serial de uma imagem de Vivian Meier nos leva a considerar como fotografia a reprodução no jornal, no livro ou na tela do computador. É claro que cada um desses meios modifica as estruturas de percepção e circulação das imagens - e muitos fotógrafos exploraram suas possibilidades e desenvolveram preferências quanto ao suporte da fotografia $^{31}-$, mas justamente 0 que caracteriza a materialidade do novo regime de visualidade é a coincidência com sua virtualidade.

Em termos filosóficos, essa posição foi parcialmente desenvolvida a partir do relativismo axiomático dos empiristas, especialmente Hume. Um pouco depois, Kant, percebendo os riscos dessa investida contra a síntese da filosofia - contra sua imagem, talvez pudéssemos dizer - estabilizou os valores e os sentidos das visões de mundo no interior de um edifício que se pretendia, explicitamente, sólido e sistemático. Seu perspectivismo se movia, assim, nos limites estreitos de uma antropologia que articulava a ideia de espécie humana à de destinação racional, dois pontos de fuga intangíveis, mas, por isso mesmo, capazes de condicionar e restringir o espectro onde a luz da Aufklärung poderia circular. ${ }^{32}$ Nessa sofrível esquematização de um dos maiores problemas da filosofia dos últimos quase trezentos anos, Nietzsche poderia aparecer, como frequentemente é o caso, como uma retomada radical do relativismo axiomático empirista, mas ele não foi o primeiro nem o mais heterodoxo nessa desestabilização.

Também aqui devemos voltar aos românticos. Entre eles, as luzes ganham uma via recusada pelo kantismo: a que reincorpora o invisível, formando com ele um binômio tensionado que é condição mesma da exigência de 
comunidade romântica. É verdade que fragmentos como aqueles dois primeiros das Ideias, de Schlegel, que afirmam, de um lado, a urgência de um tempo onde se deve "rasgar o véu de Ísis" ou "fugir", e, de outro, que o "homem espiritual [Geistlicher, também "homem religioso"] é quem vive somente no invisível" ${ }^{33}$, parecem apontar para a sacralidade do lugar da visão. Mas isso só pode ser verdadeiro se a essa dimensão estiver associada o seu oposto, ou seja, a da banalidade. 0 banal é o signo de cotidianidade sem o qual o infinito não se mostra. O capítulo "Fidelidade e gracejo [Treue und Scherz]", do romance experimental Lucinde, que Schlegel publicara em 1799, insiste no fato de que uma relação amorosa só seria possível se conjugasse "amizade, belo convívio, sensualidade e sofrimento". ${ }^{34} \mathrm{E}$ mais: contra aquilo que faz do homem uma "besta séria [ernsthafte Bestie]" é preciso instalar, justamente, as "ambiguidades [Zweideutigkeiten]" ${ }^{35} \mathrm{~A}$ ambiguidade é, portanto, o índice de um espaço de sobreposição contínua entre o visível e o invisível, e, nele, uma relação amorosa, o que significa, em termos românticos, que uma comunidade se funda no momento mesmo em que seus valores se desestabilizam e se põem em movimento. Essa disposição está presente no elogio que tanto Novalis quanto Kleist fazem à marionete como o objeto estético por excelência no teatro. Isso porque sua natureza é somente artifício, e sua luminosidade é a fronteira onde esses dois regimes se encontram. Para o primeiro, grotesca em sua estranheza, a marionete nos lembra da "necessária rudeza do cômico [nothwendige Grobheit des Lustigen]". ${ }^{36}$ Para o segundo, ela constitui o corpo ideal, na medida em que é uma prótese, como as pernas mecânicas inventadas pelos ingleses. ${ }^{37} \mathrm{O}$ momento romântico manifesta exatamente aqui sua importância na história dos regimes de visualidade. Ele permite enxergar como o esvaziamento axiomático, consequência radical e antikantiana da retomada do relativismo e do obscurecimento do referencialismo, se transforma em condição das relações intersubjetivas e, portanto, da dimensão social da imagem. Leveza e confusão são propriedades que, incessantemente, se autoimplicam. ${ }^{38}$ 
Vimos anteriormente como a disposição fantasmática própria da ontologia da imagem fotográfica rompia com a polarização verdadeiro-falso e estabelecia o regime do sentido no horizonte da ficcionalidade. Em termos sociais, o esvaziamento dos valores abriu caminho para a confusão das narrativas de identidades e, simultaneamente, para o questionamento da ordem simbólica instaurada com eles. Na fotografia, o instante cotidiano aparentemente se eterniza, mas, ao mesmo tempo, se vulgariza, em função da velocidade de circulação permitida por sua portabilidade. Essa indiferença constitutiva foi interpretada pelos primeiros defensores da fotografia - e aí podemos incluir, certamente, Arago - como seu destino democrático e progressista. Mas essa leitura representa, antes, uma versão institucionalizada do poder hermenêutico da fotografia. Não foi por acaso que essa suposta democratização foi observada, no mínimo, com reticências pelos artistas, que pressentiram nela a perda iminente de um privilégio de classe no domínio da representação. 0 grande olho social e anônimo das imagens fotográficas impõe dificuldades de controle muito diferentes daquelas que a pintura oferecia. Um quadro ou um desenho do século XVII davam a ver figuras que produziam identidades em uma circulação muito mais restrita: da mesma forma, o palácio do rei, a festa cívica, o salão de exposições, e, por fim, o museu se iluminam publicamente em ocasiões específicas, em uma economia do tempo que depende da monumentalidade da experiência visual. François Brunet mostrou como a popularização da fotografia - ou o que chamo aqui de amplitude de circulação do espaço fotográfico reorganizou os espaços sociais. Para ele, o momento que ele denomina "momento Kodak", a partir da comercialização do par câmera-filme em $1888^{39}$, marcou a conjugação das "pulsões do amador e do capitalismo" ${ }^{40}$, em uma ordem social em que uma empresa - e não o Estado - conseguiu "se identificar à noção mesma de fotografia, embaralhando de maneira concreta a economia profissional do século XIX, criando e depois capturando um mercado amador de grandes dimensões". ${ }^{41}$ Pesadelo estético de Baudelaire, Kracauer e Benjamin, tal vulgarização da imagem assinala, de fato, uma mudança 
importante no monopólio da identidade sócio-visual, operacionalizada, concomitantemente, como causa e efeito do capitalismo da belle époque. Mas somente esse último compreendeu que a mudança se produzia em um nível bem mais amplo e fundamental, e carregava consigo a possibilidade de se afirmar como crítica do próprio capitalismo: o horror da elite cultural que Benjamin instanciava ao afirmar o caráter antiestético da reprodutibilidade indefinida das fotografias é acompanhado pela admissão de seu poder revolucionário, propriamente "político". ${ }^{42}$

O coeficiente crítico das imagens fotográficas está nitidamente assinalado na destruição das fronteiras entre o vulgar e o nobre no contexto representacional. As artes visuais clássicas nunca tiveram problema algum em lançar mão do ignóbil em seus objetos. Basta olharmos um retábulo de Bosch, um ornamento gótico ou os anões de Velázquez. Seu problema, no entanto, sempre foi a representação do comum. Talvez em função da natureza do tempo que está em jogo em cada um desses casos - de tal modo que a figura, separada da existência concreta de seus modelos, tem de habitar a eternidade qualquer pêssego ou qualquer colher de pau ganhem um rictus platônico. Não podemos esquecer da admiração de Diderot diante dos quadros de Chardin, no Salão de 1763: "eles representam quase todas as frutas com os acessórios de uma refeição. É a natureza mesma. Os objetos estão fora da tela e são de uma verdade de enganar os olhos". ${ }^{43}$ Em última análise, os sonhos de uma imagem automática em Talbot ou em Daguerre ainda estavam ancorados nessa lógica da natureza mesma, e foi preciso esperar as vanguardas artísticas para que o anonimato social colocasse em questão a própria veracidade das narrativas identitárias.

Em um primeiro momento, o excesso de figurativismo das fotografias de David LaChappelle ou de Pieter Hugo parece depor contra a rejeição dos referenciais. Suas cenas são minunciosamente estudadas e posadas. De certa maneira, elas parecem retomar as narrativas das cenas domésticas pintadas no século XV por Jan Van Eyck, mergulhadas no paroxismo do 
detalhe. Ao menos é assim que Charlotte Cotton as apresenta, em um primeiro momento. ${ }^{44}$ Mas é a própria Cotton quem, em seguida, desfaz o equívoco: na fotografia contemporânea "a cena é estilizada o suficiente para que nós suspeitemos que este é um evento coreografado, funcionando como uma alegoria [...]". ${ }^{45}$ Sua análise, apesar de desaguar frequentemente em uma semiótica das mensagens visuais da fotografia, toca em um ponto importante: o caráter crítico de uma representação que, ao "estilizar" o real, purificando-o em termos visuais, acaba por tocar na estrutura contingente da realidade e, paralelamente, por denunciar os mecanismos de controle e estabilização das identidades. Não é por acaso que muitos fotógrafos de vanguarda, como Martin Parr, Juergen Teller, Helmut Newton ou Guy Bourdin tenham se envolvido, em algum momento, pelo menos, com a fotografia de moda, onde, por razões mercadológicas, todo sentido tem de caber na superfície. 0 que eles podem ter aprendido aqui é a maleabilidade infinita dessa superficialidade, e, portanto, um certo gosto pela ruptura com o profundo. Podemos comparar, sob esse aspecto, as imagens-documento da África de Sebastião Salgado à artificialidade explícita da série Nollywood, que Pieter Hugo produziu em 2008. Nessa última, atores de filmes de terror de baixo orçamento da então emergente indústria cinematográfica nigeriana são retratados caracterizados como zumbis, demônios, mercenários e outras criaturas sobrenaturais. O tensionamento que essas imagens promovem entre a narrativa ficcional e o caráter figurativo é consideravelmente mais complexo que a grandiloquência pretendida pela busca da verdade imagética de Salgado - uma complexidade que Hugo elaborou também ao retratar algumas famílias da África do Sul, com seus integrantes apertados uns contra os outros em seus pequenos sofás, na série Messina/Musina (2006) ou mesmo em The Hyena \& Other Men (2007), que apresenta nigerianos posando com hienas, macacos e cobras como se fossem animais domésticos. 0 problema central da obra de Pieter Hugo é diametralmente oposto ao de Sebastião Salgado, que se ocupa, em geral, do caráter unitário do mundo que nos cerca e da possibilidade da 
empatia. As hienas e os demônios nigerianos, nesse sentido, atestam a descontinuidade do humano e o regime rompido entre o familiar e o figurativo. Nenhum cosmopolitismo, nenhuma cosmologia, nenhuma linguagem universal. ${ }^{46}$

Restrita à sua superficialidade repetível e ironizando o estatuto regulador da representação - sem abandoná-lo completamente, mas, antes, parasitando-o - a fotografia contemporânea realiza um destino social que, de um modo ou de outro, já se deixava entrever em seus primórdios. 0 excesso figurativo da imagem fotográfica instaura a desordem no campo da semiótica e da possibilidade de circulação dos sentidos: diante dela, reconhecemos que nós mesmos não estamos mais no comando. É exatamente o que diz Julius Sachse, fotógrafo americano, filho de imigrantes alemães, ao se colocar, nos últimos anos do século XIX, diante das séries de fotografias: "poder-se-ia perder a razão ao olharmos uma imagem como essa, por assim dizer, fabricada pela própria natureza". ${ }^{47}$ Essa loucura - a mesma de Nathanael, em 0 homem da areia - faz desmoronar as fronteiras entre sujeito e objeto (esse é seu aspecto psicológico), mas também perturba o quadro geral do poder na paisagem social. Sachse foi um dos principais incentivadores da formação de um novo núcleo social em torno da fotografia, o dos amadores. Mesmo na condição de editor de revistas, patrono de museus e historiador da fotografia, ele nunca deixou de insistir no papel revolucionário e artístico das imagens produzidas por nãoprofissionais. Coerentemente, desprezava, em irônicos, mas enfáticos editoriais escritos sob o pseudônimo Snapschotte (uma blague com sua ascendência germânica), qualquer tentativa de regular o universo da fotografia amadora: expunha ao ridículo, assim, os líderes de clubes fotográficos, os júris de concursos, as pretensões dos cientistas. ${ }^{48}$ A ênfase na renovação política dos meios de circulação das imagens fez de Sachse uma das figuras mais importantes da história social da fotografia, embora, talvez pelo mesmo motivo, uma das mais esquecidas. 
A emergência do culto do amador põe em suspenso, com isso, a estabilidade da elite cultural que, até então, era condição da fruição estética das obras de arte, seja ditando suas regras, seja servindo como modelo de interioridade perceptiva. Des Esseintes, personagem principal do romance $\dot{A}$ rebours, publicado por Karl-Joris Huysmans em 1884, é o espelho exemplar desse deslocamento. Aristocrata "anêmico e nervoso" 49 , entediado e certo de que "o mundo é, em sua maior parte, composto de sacripantas e imbecis"50, ele está suficientemente desvinculado dos valores sociais para poder ter as pretensões de ser um especialista em qualquer coisa. Ao longo do romance, ele percorre, indiferentemente, a literatura, a música, a pintura, as bebidas alcóolicas, os perfumes, a geografia, e, enfim, os prazeres da sensualidade em busca de uma profundidade que, ironicamente, ele reconhece apenas para, em seguida, deixar passar, em uma narrativa tão paroxisticamente descritiva que só pôde ser considerada um romance experimental. ${ }^{51}$ Tipo ordinário e descartável, o personagem de Huysmans é uma espécie de ícone do movimento decadentista, que incluía, em alguma medida, Baudelaire e, em língua alemã, o suíço Arnold Böcklin. 0 fato é que a vulgaridade de Des Esseintes se projetava para o mundo, em geral, e para a arte, em particular, e tornava impossível qualquer sistema de valores sociais. Sua lógica é a da diáspora descentralizada das imagens fotográficas, e isso fica claro na passagem do livro em que Ernest Hello, escritor francês que produziu suas obras na mesma época em que Daguerre, é apresentado por Des Esseintes como um autor que representava seus personagens com uma vivacidade análoga à das fotografias. ${ }^{52} 0$ problema aqui é justamente que essa vivacidade é maquínica, e que, portanto, cabe nas mãos de qualquer um. Em 1889, às vésperas de sua conversão ao catolicismo, Huysmans formularia, enfim, o diagnóstico do mal que a intercessão do amador na cultura, segundo ele, havia causado: "Um dos sintomas mais desconcertantes dessa época é a promiscuidade na admiração". ${ }^{53}$

A destituição do lugar do gênio evidentemente não aniquilou os modelos identitários que operam na cultura - nesse sentido, 
Benjamin, Adorno e Horkheimer parecem ter razão ao insistirem na dominação embutida na indústria cultural. Mas, ao menos, promoveu uma crise de confiança em relação às identidades paradigmáticas do universo da arte e alterou profundamente seu regime temporal, ou seja, ampliou a topografia de circulação e relativizou a pressuposição de permanência dos objetos da cultura, dois movimentos que podem ser lidos como sinais de decadência ou de contínua mobilidade da arte. 0 que a fotografia revela, nesse contexto, é que, com ela, esses objetos são apenas imagens, que, por sua superficialidade, aprenderam a se mover (em um sentido completamente diferente do cinema), alcançaram lugares quase intangíveis - não teria sido essa a lição também da recente street art? - e passaram, quase desapercebidas. As novas teorias da arte (incluindo, talvez, essa que esboço aqui), a impressão cuidadosa dos catálogos de exposição e uma certa apropriação midiática da noção de amadorismo são, certamente, tentativas de lidar com 0 fato de que a arte aprendeu a andar; são tentativas, igualmente, de Ihe calçar sapatos e indicar o caminho. Mas o amador, além de ser uma figura social, é também seu avesso: ele aponta para a insuficiência da lógica da figuração, empurrando-a sempre para novos limites - uma espécie de fantasma político da representação.

É significativo que essa fantasmagoria da fotografia tenha sido explorada tão radicalmente no momento mesmo em que se investiu de uma intangibilidade perturbadora e se deixou confundir com outros domínios, assinalando a permeabilidade das fronteiras internas do visual. A inoculação dos problemas figurativos da imagem fotográfica no campo da pintura e do cinema exibe, mais enfaticamente, sua destinação política. Isso não quer dizer que, a uma altura qualquer da história da arte, esses domínios tenham se conjugado em uma única e mesma coisa, mas que podemos assinalar uma sobreposição fotográfica entre fotografia, cinema e pintura. ${ }^{54}$ Poucos a empreenderam de modo tão insistente quanto Andy Warhol. 
As duas frases de Warhol que se tornaram verdadeiros jargões publicitários, de tanto que foram repisadas, ganham um outro sentido quando pensadas como princípios epistemológicos. Se no futuro, todos serão mundialmente famosos por quinze minutos ${ }^{55}$ e se para entendermos Andy Warhol, basta olharmos a superfície de suas obras ${ }^{56}$, é porque esses dois elementos estão inteiramente articulados em seu incontornável relativismo axiomático. Potencializando a dinastia de Des Esseintes e Ernest Hello, Warhol esvaziou os pressupostos da arte em todos os níveis, mostrando que um retrato de Marylin Monroe ou de uma lata de sopa são, única e exclusivamente, uma superfície, e, com isso, deslizam indefinidamente no anonimato. Não podemos nos enganar aqui: é esse anonimato que, paradoxalmente, se revela como condição de uma fama que, pela sua brevidade, mais faz esquecer do que lembrar. Ser visto, ser notado, nesse contexto, não depende mais de nenhuma qualidade inerente ao objeto ou de disposições próprias de um indivíduo, mas de uma espécie de condição cosmológica, centrada na ideia de imagem em sua superficialidade. Assim, não foi por ter carregado consigo intermitentemente uma câmera - que, de resto, ele confessou não saber usar muito bem ${ }^{57}$ - ou por ter publicado vários livros de fotografias, como Exposure (1979) ou America (1985), que Warhol fez da fotografia um ponto de partida de seu trabalho, mas por sua insistência na indiferença valorativa do plano do significado imagético.

A apatia típica de Warhol - as reticências com que respondia (ou não respondia) às perguntas de seus entrevistadores foram, muitas vezes, denunciadas como uma encenação ou uma estratégia de autopromoção e não como um ethos autêntico. Para o crítico de arte Ted Hughes, por exemplo, a arte pop só poderia levar sua audiência a um estado "impotente" diante da massificação cultural. ${ }^{58} 0$ que essas críticas nunca alcançaram é que a própria autenticidade é que se coloca em jogo, e que a artificialidade de uma imagem ensaiada é, sempre, o único recurso da arte. Em uma conversa tipicamente monossilábica, lacunar e desconcertante, publicada em outubro de 1985 na revista American 
Photographer, Warhol solapa qualquer pretensão de se chegar a um critério reflexivo para os objetos de seu então recente livro de fotografias, America:

American Photography: Que critério você usou para selecionar as cerca de 300 imagens finais para o livro? Havia dezenas de milhares de negativos.

Andy Warhol: Nós escolhemos as ruins e deixamos as boas dentro da caixa.

AP: Você acha possível tirar uma fotografia ruim?

AW: Não. Toda fotografia ruim é uma boa fotografia.

AP: Então toda boa fotografia é uma fotografia ruim?

AW: Sim.

AP: Isso parece Pop. Você acha que sua fotografia é fotografia pop?

AW: Bem, sim... Todo mundo pode tirar uma boa fotografia. Todo mundo pode tirar fotografias.

AP: Então, isso torna a fotografia pop?

AW: Sim. Toda fotografia é pop, e todos os fotógrafos são loucos. ${ }^{59}$

Louco como Julius Sachse temia ficar um século antes, o fotógrafo instaura no regime da visualidade algo que em uma entrevista da década de 1960 Warhol havia chamado de "automação" ${ }^{60}$, e que não tem a ver - ou não somente a ver com a substituição do valor estético por outro, alienado, comercial. Refere-se, antes, ao imponderável do sentido e a possibilidade de seu uso. Esse espaço vazio do visual, no entanto, não é nem uma deficiência, nem um lapso momentâneo da representação a ser recuperado em um nível de figuração superior, intuitivo - como em Lucian Freud ou Francis Bacon. Ao contrário, ele é a marca imanente da incompletude das imagens, a marca de sua serialidade. Daí que o cinema de Warhol é, antes de tudo, fotográfico: a longuíssima tomada da fachada do Empire Building em Empire (1964) ou as quase seis horas de um John Giorno dormindo em Sleep (1963) inscrevem em cada fotograma a ausência da ação que o abre para um outro que será, em relação a ele, indiferenciado. Essa indiferenciação é exatamente a dimensão política da obra de Warhol. Analisando o quadro Still life, 1976, que apresenta o 
símbolo do comunismo, a foice e o martelo, em uma versão estilizada, Peter Gidal chega a uma conclusão hermenêutica bastante precisa:

[...] essa imagem, assim, ao contrário de muitas outras, não é uma analogia para alguma caracterização de emoções ou expressões, que é, por sua vez, um duplo da persona(lidade) [person(ality)], de uma série de humanizações e antropomorfismos que se levariam para ser identificados em profundidade. Todo o conceito de identificação é problemático, enquanto força que impele o movimento da posição de alguém em um espaço social ou político de significados sociais na direção e para dentro de uma residência humana diferente - outro corpo ou outra figura - onde os fantasmas e fantasias, as realidades das projeções de alguém, são encenadas. [...] Assim, o mecanismo de produção de constantes perturbações na identificação, de impedimento de lugares seguros para ela, e de interrupções e rupturas não-calculadas, é, no mínimo, uma tentativa de impossibilidade ou de antagonismo. 0 próximo passo, é claro, é produzir obras anti e não-identificatórias, combatendo a estrutura da identificação como um sistema 'necessário'" ${ }^{61}$

O que Gildal talvez não pudesse - ou não quisesse reconhecer era que esse combate já havia sido empreendido, e isso em um nível político bastante explícito. É verdade que ele não tinha a forma ideológica do comunismo clássico, pois precisava perverter sua própria estrutura voluntarista. A famosa entrevista de Warhol a Gene Swenson, de 1963, onde ele afirma que acreditava, um pouco como Brecht, que todos deveriam ser iguais, mas que - muito diferentemente deste - desejava que isso fosse alcançado pela despersonalização, pela transformação das pessoas em "máquinas"62, torna inquestionável a dimensão social da crítica operada pela arte pop. Em sua indiferença, a repetição da série fotográfica faz com que cada imagem seja dupla ${ }^{63}$ : a mesma e uma outra, e, ao mesmo tempo, instala a indiscernibilidade entre lojas de departamento e museus. ${ }^{64}$ Uma paisagem social que deixaria Huysmans assombrado. 


\section{Referências bibliográficas}

ANDRIOPOULOS, Stefan. Ghostly Apparitions: German Idealism, the Gothic Novel, and Optical Media. New York: Zone Books, 2013.

BENJAMIN, Walter. "Das Kunstwerk in Zeitalter seiner technischen Reproduzierbarkeit" In.: Gesammelte Schriften, Bd. I-2. Frankfurt am Main: Suhrkamp, 1991.

BERG, Gretchen. "Andy: My True Story". Los Angeles Free Press, 17/03/1967.

BORNHEIM, Gerd. "Introdução à leitura de Winckelmann". In: Páginas de filosofia da arte. Rio de Janeiro: Uapê, 1998.

BRUNET, François. La naissance de l'idée de photographie. Paris: PUF, 2012.

BURKE, Peter. Eyewitnessing, the Uses of Images as Historical Evidence. London: Reaktion, 2001.

COTTON, Charlotte. The Photograph as Contemporary Art. London: Thames \& Hudson, 2014.

DIDEROT, Denis. “Salon de 1763”. In: Oeuvres, t. IV. Paris: Robert Laffont, 1996.

DIDI-HUBERMAN, Georges. Invention de I'hystérie: Charcot et l'iconographie photographique de la Salpêtrière. Paris: Macula, 1982.

FLYNN, Marcy Silver. "Amateur Experiences: Julius Sachse and Photography" Pennsylvania History, v. 64, n. 2 (1997), p. 333348.

FONT-RÉAULX, Dominique de. Peinture et photographie. Les enjeux d'une rencontre, 1839-1914. Paris: Flammarion, 2012.

FOUCAULT, Mieehl. Les mots et les choses. Paris: Gallimard, 1966. 
FRIEDLÄNDER, Max Jakob. “Die Königlichen Kunst- und Altethums-Sammlungen bis zum Jahre 1830". In: Zur Geschichte der Königlichen Museen in Berlin - Festschrift zur feier ihres funfzigjährigen Bestehens. Berlin: s/e, 1880.

GILDAL, Peter. "Some Problems Relating to Andy Warhol's Still Life 1976". In: FRANCIS, M. (org.), Andy Warhol: The Late Work. München: Prestel Verlag, 2004.

GOLDSMITH, Kenneth. (org.), I'll Be Your Mirror: The Selected Andy Warhol Interviews. New York: Carroll \& Graf, 2004.

GROJNOWSKI, Daniel. À rebours, de K.-J. Huysmans. Paris: Gallimard, 1996.

HACKETT, Pat. (org.) The Andy Warhol Diaries. New York: Warner Books, 1989.

HARVEY, John. Photography and Spirit. London: Reaktion Books, 2007.

HUGHES, Robert. "On Lucian Freud". In: Lucian Freud Paintings. New York: Thames and Hudson, 1987.

HOFFMANN, E. T. A. Poetische Werke in sechs Bänden. 6 Bde. Berlin: Aufbau, 1963.

HUYSMANS, Joris-Karl., À rebours/Le drageoir aux épices. Paris: Christian Bourgeois, 1975.

HUYSSEN, Andreas. Present Pasts: Urban Palimpsests and the Politics of Memory. Stanford: Stanford University Press, 2003.

JÄGER, Jens. Gesellschaft und Photographie: Formen und Funktionen der Photographie in Deutschland und England 18391860. Wiesbaden: Springer Fachmedien, 1995.

JOHNSON, William S. et. al. A History of Photography. Köln: Taschen, 2012.

KANT, Immanuel. Kritik der Urteilskraft. Werke, Bd. 8. Darmstadt: Wissenschaftliche Buchgesellschaft, 1983. 
KAUFMANN, Thomas. "Antiquarianism, the History of Objects and the History of Art before Winckelmann" Journal of the History of Ideas, v. 62, n. 3(2001), p. 523-541.

KLEIST, Heinrich von. Sämmtliche Werke und Briefe, 3 Bde. München: Carl Hanser, 2011.

KRAUSS, Rosalind. "Photography's Discursive Spaces". In:

The Originality of the Avant-Garde and Other Modernist Myths. Massachusetts: MIT Press, 1996.

LEMOS, Fabiano. "Modos de habitar a história, ou Filosofia, cultura e arquitetura na fundação do Altes Museum de Berlim". Archivos analiticos de politicas educativas, v. 19, n. 2 (2011).

MAIGNON, Claire. Le salon et ses artistes. Paris: Hermann, 2009

NIETZSCHE, Friedrich. Sämtliche Briefe. Kristische Studienausgabe in 8 Bänden. Edição organizada por Giorgio Colli e Mazzino Montinari. Munchen, Berlin und New York: Deutscher Taschenbuch Verlag und Walter de Gruyter, 1986.

NOVALIS. Werke, Tagebücher und Briefe, 3 Bde., 2. Aufl. München: Carl Hanser, 2005.

PARR, Martin. "Photo Painting in Northeast Brazil". In: PARR, Martin; RIEDL, Titus. Retratos pintados. Portland: Nazraeli Press, 2010.

RANK, Otto. Der Doppelgänger. Wien: Internationaler Psychoanalytischer Verlag, 1925.

RECHT, Roland. La lettre de Humboldt: du jardin paysager au daguerreotype. Paris: Christian Bourgois, 2006.

RIEGER, Angelica. Alter Ego: der Maler als Schatten des Schriftstellers in der französischen Erzählliteratur von der Romantik bis zum Fin de siècle. Köln: Böhlau, 2000.

ROSENBLUM, Naomi. A World History of Photography. New York/ London: Abbeville Press, 2007. 
SCHLEGEL, Friedrich. Lucinde. In: Kritische Friedrich-SchlegelAusgabe. Erste Abteilung: Kritische Neuausgabe, Band 5. München, Paderborn, Wien, Zürich: Ferdinand Schöningh Verlag,1962.

SCHUMAN, Aaron. "Beholder". In: HUGO, Peter. This Must be the Place. München: Prestel, 2012.

SHAPIRO, Fred. The Yale Book of Quotations. New Haven: Yale University Press, 2006.

STARN, Randolph. "Seeing Culture in a Room for a Renaissance Prince”. In: HUNT, Lynn. (org.) The New Cultural History. Berkeley/ London: University of California Press, 1989.

WARHOL, Andy. America. New York: Penguin, 2011.

WARHOL, Andy; HACKETT, Pat. POPism, The Warhol Sixties. Orlando: Harcourt, 1980.

Fabiano Lemos é professor do Departamento de Filosofia da UERJ

${ }^{1}$ Cf. ANDRIOPOULOS, 2013, p. 42 e ss.

${ }^{2}$ HOFFMANN, 1963, Bd. 2, p. 378.

${ }^{3}$ HOFFMANN, 1963, Bd. 2, p. 378.

${ }^{4}$ HOFFMANN, 1963, Bd. 1, p. 133.

${ }^{5}$ HOFFMANN, 1963, Bd. 2, p. 372.

${ }^{6}$ HOFFMANN, 1963, Bd. 2, p. 410.

${ }^{7}$ Cf. HARVEY, 2007, p. 107-108.

${ }^{8}$ Cf. HARVEY, 2007, p. 87.

${ }^{9}$ Cf. HARVEY, 2007, p. 89.

${ }^{10}$ Cf. DIDI-HUBERMAN, 1982, p. 92

${ }^{11}$ C f. HARVEY, 2007, p. 76.

${ }^{12}$ HARVEY, 2007, p. 58.

${ }^{13}$ RANK, 1925, p. 18.

${ }^{14}$ Cf. ROSENBLUM, 2007, p. 198-199; JOHNSON et. al., 2012, p. 48

${ }^{15}$ KRAUSS, 1996, p. 139.

${ }^{16}$ Cf. BRUNET, 2012, p. 213-267. 
${ }^{17}$ ROSENBLUM, 2007, p. 27.

${ }^{18}$ PARR, 2010, p. 1

${ }^{19}$ DIDI-HUBERMAN, 1982, p. 150.

20 JÄGER, 1995, p. 148; cf., também, BURKE, 2001, p. 26.

${ }^{21}$ NIETZSCHE, 1986, Bd. 2, p. 307.

${ }^{22}$ Cf. RIEGER, 2000, p. 249-250.

${ }^{23}$ Cf. FONT-RÉALX, 2012, p. 230-233.

${ }^{24}$ Cf. FRIEDLÄNDER, 1880, pp. 17 e ss.; HUYSSEN, 2003, p. 11-29.

${ }^{25}$ STARN, 1989, p. 207.

${ }^{26}$ Cf. MAIGNON, 2009, p. 13.

27 Cf. BORNHEIM, 1988; KAUFMANN, 2001. E é por isso também que Friedrich Schlegel recorre à figura de Winckelmann, tornando-a índice sagrado de uma certa configuração do olhar na produção de uma imagem do homem que, como a estátua semidestruída do torso de Belvedere, era aberta, mas infinita. 0 fragmento 102 do conjunto Ideias, publicado na revista Athenäum em 1800, marca toda a diferença entre o hegelianismo e o romantismo subversivo de Schlegel: "O primeiro entre nós que teve a intuição intelectual da moral e que reconheceu e, divinamente inspirado, anunciou o modelo [Urbild] da humanidade perfeita nas formas da arte e da antiguidade, foi o santo Winckelmann" (SCHLEGEL, 1988, Bd. 2, p. 230).

${ }^{28}$ Cf. LEMOS, 2011, p. 15.

${ }^{29}$ Cf. FOUCAULT, 1966, p. 19-31.

${ }^{30}$ Cf. KRAUSS, 1996, p. 133.

${ }^{31}$ Podemos tomar como exemplo a obra de Lewis Hine, que, na primeira década do século $\mathrm{XX}$, ao fotografar as condições de vida das crianças operárias, elaborou uma estética apropriada aos panfletos e cartazes onde essas imagens foram publicadas (cf. ROSENBLUM, 2007, p. 377-378).

${ }^{32}$ Esse predomínio da linha como limite restritivo no pensamento de Kant está presente de modo exemplar em sua estética, especialmente na passagem da Analítica do belo, da terceira Crítica, onde se lê: "na pintura, na escultura, enfim, em todas as artes plásticas [bildenden Künsten], na arquitetura, na jardinagem, na medida em que são belas artes, o desenho [Zeichnung] é o essencial (...) (KANT, 1983, p. 305).

${ }^{33}$ SCHLEGEL, 1988, Bd. 2, p. 223.

${ }^{34}$ SCHLEGEL, 1962, p. 34.

${ }^{35}$ SCHLEGEL, 1962, p. 33.

${ }^{36}$ NOVALIS, 2005, Bd. 2, p. 773.

${ }^{37}$ KLEIST, 2011, Bd. II, p. 428.

${ }^{38}$ Os termos Verwirrung e Verworrenheit, que traduzo, nesse contexto, indistintamente por confusão, são centrais em Schlegel e Novalis. Em Lucinde, fala-se de uma "confusão romântica" como a experiência que o 
personagem Julius tem na união com sua amada (SCHLEGEL, 1962, p. 6). 0 fragmento 54 do Pólen, de Novalis, assinala a transformação dos "homens confusos [Die Verworren]" em um modelo pedagógico (NOVALIS, 2005, Bd. 2, p. 249). Vê-se que, em ambos os casos, uma dimensão social é parte significativa do problema.

${ }^{39}$ cf. BRUNET, 2012, p. 233-243.

${ }^{40}$ Cf. BRUNET, 2012, p. 227.

${ }^{41}$ BRUNET, 2012, p. 216.

${ }^{42}$ BENJAMIN, 1991, p. 442.

${ }^{43}$ DIDEROT, 1996, p. 264.

${ }^{44}$ COTTON, 2014, p. 50.

${ }^{45}$ COTTON, 2014, p. 51.

${ }^{46}$ Sobre a obra de Pieter Hugo e sua relação com a narratividade, cf. SCHUMAN, 2012, p. 219-223.

${ }^{47}$ Citado em RECHT, 1989, p. 140.

${ }^{48}$ Cf. FLYNN, 1997, p. 333-348.

${ }^{49}$ HUYSMANS, 1975, p. 48.

${ }^{50}$ HUYSMANS, 1975, p. 54.

${ }^{51}$ Cf. GROJNOWSKI, 1996, p. 116-144.

${ }^{52}$ Cf. HUYSMANS, 1975, p. 248

${ }^{53}$ HUYSMANS, 2008, p. 243.

${ }^{54}$ Poderíamos dizer, também, que há uma sobreposição cinematográfica e uma outra, pictórica, entre esses campos, cada uma organizando os sentidos do discurso sobre as artes de uma maneira particular e carregando problemas específicos que não podem ser os mesmos em cada caso.

${ }^{55}$ A frase "In the future, everybody will be world famous for fifteen minutes" aparece em uma brochura distribuída por ocasião de uma exposição de Warhol em 1968 na Suécia, com o temo "world" frequentemente esquecido nas citações posteriores. É possível que a ideia da frase tenha sido em parte dada pelo crítico de arte George Rickey ou de outro crítico, Philip Pearlstein. Sobre a controvérsia em torno da frase, cf. SHAPIRO, 2006, p. 797. 0 fato é que Warhol utilizou, ele mesmo, muitas versões da frase, e, em uma entrada de seu diário, em 27 de julho de 1978, ele afirma se divertir com as inúmeras variantes empregadas, involuntariamente, pelas pessoas ao citá-lo (cf. HACKETT, 1989, p. 156).

${ }^{56}$ A frase "If you wanna know all about Andy Warhol, just look at the surface of my paintings and my films and me, and there I am" é citada em BERG, 1967, p. 3.

${ }^{57}$ Cf. WARHOL \& HACKETT, 1980, p. 93.

${ }^{58}$ HUGHES, 1987, p. 8.

${ }^{59}$ GOLDSMITH, 2004, p. 314-315. 
${ }^{60}$ GOLDSMITH, 2004, p. 59-62.

${ }^{61}$ GILDAL, 2004, p. 52-53.

${ }^{62}$ GOLDSMITH, 2004, p. 16.

${ }^{63}$ WARHOL, 2011, p. 22.

${ }^{64}$ Devemos lembrar de uma das primeiras entrevistas de Warhol, em que ele afirma exatamente isso: "lojas de departamento são um pouco como museus" (GOLDSMITH, 2004, p. 23). Tal indiferença foi formulada também por Foucault: " Haverá um dia em que a própria imagem, com o nome que carrega, será desidentificada pela similitude indefinidamente transferida ao longo de uma série: Campbell, Campbell, Campbell” (FOUCAULT, 1973, p. 79). 